\title{
Potential for Biofuel-based Greenhouse Gas Emission Mitigation: \\ Rationale and Potential
}

By

\author{
Bruce A. McCarl ${ }^{1}$ \\ Dhazn Gillig ${ }^{2}$ \\ Heng-Chi Lee ${ }^{3}$ \\ Mahmoud El-Halwagi ${ }^{4}$ \\ Xiaoyun Qin ${ }^{4}$ \\ Gerald Cornforth ${ }^{1}$
}

${ }^{1}$ Department of Agricultural Economics, Texas A\&M University

${ }^{2}$ American Express Corporation

${ }^{3}$ Department of Economics, University of Western Ontario

${ }^{4}$ Department of Chemical Engineering, Texas A\&M University

The work underlying this chapter was supported by USDA, USEPA, USDOE, SANREM and the Texas Agricultural Experiment Station.

This will be a chapter in a forthcoming proceedings volume edited by J. Outlaw and K. Collins arising from the USDA and Farm Foundation sponsored conference entitled Agriculture as a Producer and Consumer of Energy that occurred in Washington D.C., June 24-25, 2004. 


\section{INTRODUCTION}

The Intergovernmental Panel on Climate Change (IPCC) asserts that the Earth's temperature rose $0.6^{\circ} \mathrm{C}\left(1^{\circ} \mathrm{F}\right)$ during the $20^{\text {th }}$ century and projects that temperature will continue to rise with a forecast increase ranging from 1.5 to $4.5^{\circ} \mathrm{C}$ by 2100 (IPCC, 2001a). The IPCC also asserts that man-made, anthropogenic greenhouse gas emissions (GHGE) are the dominant causal factor (IPCC 2001,a,b). In response, society is actively considering options to reduce net GHGE.

Emission reductions can be expensive to achieve and take time to develop. According to the EPA Emissions Inventory for the US emissions in 2002 79\% of the country's emissions arose from the combined emissions from electricity generation (33\%), transportation (27\% ) and industry (19\%) [USEPA (2004)]. The EPA inventory also estimates that carbon dioxide emissions from fossil fuel consumption amount to $80 \%$ of all US GHG emissions. Given such an origin for GHGE, a large reduction would require less energy use, development of new technologies, or fuel switching including biofuel usage. Biofuel feedstocks are a source of raw material that can be transformed into petroleum product substitutes in liquid energy usages or used as a direct input to power plants substituting for coal.

In the USA, liquid fuel biofuel production has not proven to be broadly economically feasible with maize-based ethanol being the dominant, but highly subsidized example. Power plant substitution has proven feasible, but only in areas with ready supplies of low cost feedstocks (generally cogeneration from wood milling or pulping residues). Widespread production is unlikely under either alternative in the near future in the absence of some form of subsidy.

Schneider and McCarl (2003) list four possible outcomes of expanded biofuel production that could justify subsidization: 
- A widespread biofuel market would support agricultural prices and incomes by adding to demand replacing other forms of farm income support.

- Replacement of some fuel components with ethanol has desirable environmental attributes and its widespread use in place of methyl tertiary-butyl ether (MTBE), for instance, would be environmentally desirable. A similar environmental motivation involves replacement of coal and its inherent mercury content with mercury free biomass feedstocks.

- Substitution of biofuel-based products for petroleum reduces dependence on imports and contributes to energy security.

- Biofuel combustion substantially offsets net GHG emissions by the recycling of carbon. Current levels of GHG emissions are beginning to be judged as undesirable at current levels.

Government pursuit of some mix of these outcomes could justify biofuel related actions.

In this chapter, we examine the first and last of the four motivations from institutional and quantitative viewpoints. The institutional section discusses the context in which offsets may be needed and the role that agriculture and forestry may play with an emphasis on biofuels. The quantitative portion extends the work of McCarl et al. (2000) and Schneider and McCarl (2003) to further consider the potential of biofuel and other possible agriculture/forestry GHG offset alternatives in the face of a range of greenhouse gas offset prices emphasizing dynamics.

\section{GREENHOUSE GAS POLICY AS MOTIVATION FOR BIOFUELS}

In the recent past, substantial scientific endeavor has been directed toward understanding and forecasting the linkage between GHGEs, climate change, and economic activity. The IPCC scientific based assessments, as they have arisen over time, report an evergrowing consensus scientific opinion that over the last 100 years a $0.6^{\circ} \mathrm{C}$ warming has 
been observed and that in the foreseeable future increasing concentrations of GHGs will cause a substantial degree of climate warming (IPCC, 2001b). Atmospheric concentrations of carbon dioxide $\left(\mathrm{CO}_{2}\right)$, the most abundant GHG, are forecast to increase by 90 to 250\% over pre-industrial levels by the end of the 21st century (IPCC, 2001b). Such large concentrations coupled with increases in other GHGs are predicted to cause substantial rises in global temperatures (Watson (2000) elaborates) along with accompanying alterations in precipitation patterns.

Numerous scientific efforts have tried to predict the impact of such a climate shift. Predictions to date suggest GHG concentration increases will alter economic and environmental attributes of agriculture, forestry, energy, human diseases, coastal resources, ecosystems, and water availability among many other impact categories. One way to partially avoid prospective climate change or climate change risk is by reducing the amount of GHGs in the atmosphere. The IPCC documents present compelling arguments that, while it will be a long time before we know the exact effects of climate change, future reductions in GHG concentrations will take a very long time to be achieved and that perhaps as a precautionary move the USA should begin reduction efforts now. The increase in atmospheric GHG concentrations is largely caused by rising emissions from a diverse set of sources including emissions from fossil fuel combustion, deforestation, agricultural land use changes and land degradation. A reduction in the rate of GHGEs would reduce future atmospheric concentrations. In the face of such evidence, society has begun to consider actions to reduce net GHGE. The USA, along with most of the developed world, is a member of the United Nations Framework Convention on Climate Change (UNFCCC), which has the stated objective of stabilizing atmospheric GHG concentrations. The USA is also among the signatories to the UNFCCC generated international agreement called the Kyoto Protocol (KP), which mandates actions reducing GHGEs (United Nations Framework Convention on Climate Change, 1998). However, in 2002, President George W. Bush announced a US 
unilateral program called the Clear Skies Initiative that among other things states a policy goal of reducing future GHGE (Bush, 2002).

The amounts of GHGE reduction that are being considered are substantial. If fully ratified, the KP would have required that the USA achieve a 7\% reduction in net GHGEs relative to 1990 levels by a 2008-2012 commitment period. While the Clear Skies initiative would require an 18\% reduction in GHGE per dollar of gross domestic product by 2012. The effective required KP GHGE cut as of the commitment period would be substantially larger than 7\%, considering the growth in emissions that would occur between 1990 and the commitment period. Considering likely growth levels, the emissions reduction rises to roughly a 30\% cut in anticipated net GHGEs as of the commitment period, in the absence of any reduction effort. Pew Center estimates place the Clear Skies GHGE reduction as a "very modest improvement over the "business as usual" emissions projections for 2012 ..., it appears to continue the same trend of GHGintensity reductions and GHG emissions increases experienced over the last two decades" and assert that "Emissions in 2012 would be 30 percent above 1990 levels" as opposed to the Kyoto commitment that would have been 7 percent below 1990 (Pew Center, 2003).

Greenhouse gas emissions reductions in a biofuel or other context may also be motivated for several other reasons.

- Adoption of a precautionary stance toward climate forcing -- The exact incidence of climate change, the degree of forcing caused by incremental emissions, the economic implications thereof, and the reversibility of deleterious effects are highly uncertain. It may be desirable to adopt a go slow, precautionary stance to slow down potential GHGE forcing of climate change and preserve societal options motivated by the uncertainties involved with GHGE forcing.

- International pressures on emissions - The USA has been estimated (depending on accounting stance) to be emitting as much as $40 \%$ of global GHGs. Other 
countries have expressed opinions that US emissions are excessive and have begun to place international pressure on the USA to reduce GHGE. Actions to reduce US emissions may be desirable to facilitate international affairs, trade negotiations, and other cooperation.

- Domestic policies directed toward pollution - The Clear Skies and other federal governmental initiatives indicate that future actions will be needed to reduce GHGE along with sulfur oxides, nitrous oxides, and mercury. All of these would be addressed by forms of biofuel usage. A number of states have also adopted regulatory stances or policy goals that also promote changes in emissions.

- Industry planning under uncertainty -- Industry in the USA is faced with an uncertainty today as to whether greenhouse gas emission limits will be imposed in the next 10 to 20 years. Multinational corporations (which are common in the energy component of industry as well as in the other emitting sectors) face a higher degree of certainty of emission caps for operations in Europe and other parts of the industrialized world. This uncertainty places a large part of their business assets at risk. For example, assuming that an eventual cap of 7\% below 1990 levels is imposed and that energy use growth continues until the time that the cap is imposed, it is not unreasonable to think that industry faces a substantial chance of needing to operate in a world where by 2010 emissions need to be $30 \%$ or so smaller than they would have been. This would put at risk $15 \%$ of gross sales, facilities etc. Many firms have started the quest to discover ways to reduce GHGE in an economically sound manner.

- Need for cheap emission offsets -- The previously stated reasons for GHGE offsets involve considerations that would cause emitters in the USA to reduce net GHGEs via choices from a broad set of emission reduction and offset alternatives. Such forces would not necessarily favor agricultural options 
including biofuels. Rather, any emission reduction possibility would do. However, focused interest on biofuel and other agricultural alternatives has arisen because of anticipated relatively low per metric ton (MT) carbon costs and a feeling that adjustments can be made in a relatively short time frame. A number of biofuel and other agricultural GHGE related strategies are currently in use without any GHGE related program in place. Furthermore, some of the strategies involve existing, well-known technologies which could be adopted in the near term as opposed to a number of energy sector strategies which require costly and time-consuming technological innovation and/or engineering efforts to reduce implementation costs. Industrial concerns are interested because the availability of cheap GHGE offsets may allow them to avoid making large investments to directly capture and store $\mathrm{CO}_{2}$.

- Congruence of effects of expanded use of biofuel and other agricultural GHG offsets with other policy desires -- Many of the potential agricultural GHGE reducing practices have been previously encouraged in US government agricultural programs designed to achieve environmental improvements and agricultural income support. Conservation incentives involving reduced tillage have been present in recent agricultural farm bills and have been justified on the basis of environmental improvement and agricultural income support. Bioenergy provisions have also been present with motivations involving energy security. Many of the potential practices both involve direct support payments to farmers and have supply control characteristics which tend to lower aggregate production and raise market prices. Water quality and soil erosion programs have also been undertaken which involve GHGE reducing practices. World Trade Organization (WTO) regulations also contribute to the desirability of GHG related payments as a form of farm income support. 
- Development of another market for farm products - The above motivations largely cover factors, which stimulate action or concern on the behalf of general society and policymakers. Agricultural producers are also interested. Proposed GHG policies such as the KP allow for direct expanded product markets wherein biofuel feedstocks could be sold along with access to emissions trading markets. Offset producers could sell GHGE offset credits to those in need of GHGE reductions or rights both generating income-enhancing opportunities. It is also likely that market demand in those arenas would be much more elastic than conventional agricultural markets. Economically this would generate welfare gains accruing to producers.

\section{BIOFUELS AS A GHG OFFSET}

Biofuel production can provide an important GHGE offset. Namely biofuels mitigate GHG emissions because their usage displaces coal and oil essentially entering into a carbon recycling operation. As plants grow, they remove $\mathrm{CO}_{2}$ from the atmosphere via photosynthetic processes. In turn, when the biofeedstocks or their derivative fuels are combusted, the carbon is released into the atmosphere. Fossil fuel use, on the other hand, releases $100 \%$ of the contained carbon. The net GHGE consequences of a biofuel then depend on the amount of fuels from fossil sources used in producing the biofuel energy in the form of petroleum and coal-based electrical energy to raise, transport, and process the feedstock into energy. Net carbon emissions from a poplar fed power plant amount to approximately 5\% of the emissions from an energy equivalent amount of coal (Kline, et al., 1998). Ethanol replacement relative to petroleum yields a lower offset rate. 


\section{AGRICULTURAL AND FORESTRY GHGE OFFSET POSSIBILITIES}

There are a number of opportunities to pursue GHGE offsets above and beyond the employment of biofuel practices. These include pursuit of GHGE offsets in the agricultural sector broadly defined to include forests. Following the arguments in McCarl and Schneider (2000), there are at least three ways agriculture may participate in GHGE offset enhancement efforts.

- Agriculture may reduce GHG emissions generated during operations.

- Agriculture may enhance absorption of GHGE by creating or expanding sinks as has commonly been called carbon sequestration.

- Agriculture may provide products, which substitute for GHGE intensive products displacing emissions largely in the form of biofuels but also in the form of other product substitution.

The first and second of these and the non biofuel aspects of the third are the principal agricultural opportunities we discuss here.

\section{Emission reductions}

In terms of emission reductions, IPCC (1996) estimates that globally agriculture emits about $50 \%$ of all methane $\left(\mathrm{CH}_{4}\right)$ emissions, $70 \%$ of all nitrous oxide $\left(\mathrm{N}_{2} \mathrm{O}\right)$, and $20 \%$ of all $\mathrm{CO}_{2}$. Sources of $\mathrm{CH}_{4}$ emissions include rice, ruminants and manure. These sources can be reduced by altering items such as crop mix, livestock herd size, livestock feeding and rearing practices, and manure management. $\mathrm{N}_{2} \mathrm{O}$ emissions come from manure, legumes, and fertilizer use and can be reduced by altering items such as livestock herd size, crop mixes, and fertilization practices. $\mathrm{CO}_{2}$ emissions arise from fossil fuel usage, soil tillage, deforestation, biomass burning, and land degradation. $\mathrm{CO}_{2}$ emissions can be reduced by altering items such as production fuel use, allocation of land between crops, pasture, grass lands and forests, forest harvest rates, crop residue management, forest harvest management, and land restoration. McCarl and Schneider (2000) present a further discussion of and a review of the types of activities that can be pursued as do the 
US Environmental Protection Agency (US EPA) documents on methane and gas emission inventories (2000). On the forest side, management practices that offset emissions according to Brown et al. (1996) and Brown (1999) include reduced deforestation or logging, protection of forests in reserves, and reduced disturbances by managing forest losses through fire and pest outbreaks.

The relative magnitude of these emission sources varies substantially across countries, with the greatest differences between developing and developed countries.

Deforestation and land degradation mainly occurs in developing countries. Developed country agriculture generality uses more energy, intensive tillage systems, and fertilizer, resulting in $\mathrm{CO}_{2}$ fossil fuel-based emissions, carbon emissions from more intensive tillage, $\mathrm{N}_{2} \mathrm{O}$ emissions from fertilizer, and $\mathrm{N}_{2} \mathrm{O}$ plus $\mathrm{CH}_{4}$ emissions from animal herds and resultant manure.

\section{Sequestration/Sink Enhancements}

There are two major types of actions that can be employed to pursue sequestration. These involve agricultural and forestry management changes and changes in land use.

Changes in Agricultural Land Management

The most commonly discussed agricultural management sequestration enhancing changes involve tillage and, nutrient and residue management. These involve reductions in tillage intensity (adopting conservation tillage or no-till), adding organic manure, altering fertilization and/or somehow leaving behind more crop residues. Strategies have also been mentioned which involve changing rotations, altering crop mixes, employing more perennials, growing crops with more above ground biomass, using winter cover crops, and utilizing erosion control techniques such as terracing, contour 
plowing, strip cropping, buffer strips, and water management. (Lal et al. (1998) cover the crop lands topic in much more detail).

Agricultural carbon sequestration (ACS) can also be stimulated by changes in pasture and rangeland management which involve altering plant species on pasture lands, improving grass productivity, reducing grazing intensity, employing fertilization, or otherwise altering management so as increase the amount of organic manner incorporated into the soil. (Follett et al. (2000) cover the grazing lands topic in much more detail).

Forest Management Options

Forest management practices that can be altered to increase carbon retention can be classified into several groups:

- Management to retain carbon in forests including longer rotations, reduced deforestation or logging, protection of forests in reserves, reduced impact logging, and reduced disturbances by managing forest losses through fire and pest outbreaks (Brown et al. (1996); Brown (1999); and Murray (2000) elaborate).

- Management for increased carbon in standing forest biomass or forest soils through use of enhanced silvicultural treatments, natural or artificial regeneration in secondary forests and other degraded forests whose biomass and soil carbon densities are less than their maximum value (Brown et al. (1996) and Brown (1999) elaborate)

- Altered management and use of harvested wood products shifting demand into longer lasting wood products, and extending the lifetime of wood products through disposal, recycling and other preservation efforts (Brown et al. (1996); Brown (1999); and Skog and Nicholson (2000) elaborate).

Changes in Land Use

Carbon sequestration may also be increased by changing land use. Generally uses that disturb the soil less often enhance sequestration. Thus, the strategies that have been prominently discussed include 
- Afforestation of non-forested agricultural or other lands and increased tree cover on agricultural or pasture lands through agroforestry.

- Conversion of croplands to grasslands, pasture, rangelands or wetlands.

- Restoration of degraded lands, in an effort to re-establish their organic content.

\section{Substitute product-based GHG offsets beyond biofuels}

Agricultural products may be grown which replace fossil fuel intensive products. One such product category involves biomass for energy generation or transformation into liquid fuels. Forestry products can also be used to substitute for fossil fuel intensive use of steel and concrete in construction. (Brown et al. (1996); Marland and Schlamadinger, (1997); and Brown (1999) elaborate). Finally, there may be gains from substituting cotton and other fibers for petroleum-based synthetics.

\section{FACTORS AFFECTING THE COMPETITIVENESS OF BIOFUELS}

The amount of subsidy, the extent of biofuel penetration into the energy market, and the rate of technical progress are key considerations in future biofuel prospects. In this study, the only form of subsidy considered is in the form of a carbon price which may not be a subsidy at all but rather a reflection of the future externality cost of GHGE into

the atmosphere. Namely, if a prospect offsets $95 \%$ of the carbon created from an energy equivalent amount of fossil fuel then at a \$40 per MT carbon price this amounts to a \$38 a MT subsidy. Because wood is about 50\% carbon, this would be a \$19 per MT implicit subsidy and relative to a wood price in the vicinity of \$25 to \$30 per MT, this substantially offsets the purchase price to a biofeedstock user.

Energy market penetration of biofuels is similarly important. Biofuels can penetrate when new plants are built or older plants are retrofit. New power or petroleum refining plants are needed as existing plants are retired or as demand for energy use grows.

Technical change is also important. Agricultural productivity has grown over time. 
Progress in biofeedstock yields whether at the farm level or in the form of conversion ratios to energy products will be important to maintain a competitive role.

\section{GHG OFFSET POTENTIAL ANALYSIS REQUIREMENTS}

The agricultural and forestry (AF) sectors are complex and highly interrelated. A number of features of these sectors influence the needed form of analytical approach to assessment of AF GHGE mitigation potential. In particular, the features that we take note of involve dynamics, multiple gas implications, mitigation alternative interrelatedness, co-benefits, market/welfare implications, and differential offset rates. The importance of each factor will be addressed below.

Dynamics - Agricultural and forestry activities develop over time. Forest and longer term perennial usage diverts resources from other usages. Carbon is sequestered in AF ecosystems as long as carbon addition exceeds decomposition. However, as carbon accumulates, decomposition rates rise. Eventually sequestration will stop. Biofuel feedstocks take years to mature. Examination of sequestration and biofuels requires attention to these dynamics.

Multiple gas implications - GHGE mitigation strategies impact emissions of $\mathrm{CO}_{2}, \mathrm{~N}_{2} \mathrm{O}$, and $\mathrm{CH}_{4}$. These gasses have different effects on climate change radiative forcing. Equivalency rates have been established. This chapter uses 100 year global warming potentials as suggested in Reilly et al. (1999).

Mitigation alternative interrelatedness - The AF mitigation alternatives are linked in many ways. Modeling must be complex, depicting intermediate products, product substitution, and competition for land, among other factors across the AF sectors.

Co-Benefits - AF mitigation alternatives directly affect environmental pollutant loadings, water usage, animal habitat, and many other environmental processes. 
Market/welfare implications. The USA exhibits large production relative to domestic needs and total global market volume for many commodities. Therefore, the commodity production and price effects of US GHGE mitigation policies will also affect prices and welfare in domestic and world markets.

Differential offset rates. The AF GHGE related strategies exhibit substantially different GHG offset rates. For example, tillage changes produce about 0.625 metric tons of carbon offsets per hectare while still producing crops. Forests or biofuels can produce offset rates above 2.5 tons but with no complementary crop production. Furthermore, these offset production rates vary over time. At low offset prices, complementary production is likely to be favored. Under discounting, near term offsets will be favored over longer term offsets. This implies a need to look at offset price and timing characteristics when a strategy becomes dominant.

\section{MODELING}

In order to investigate the dynamic role of agriculture and forest carbon offsets including biofuels and other alternatives, an analytical framework is needed that can depict the time path of offsets from agricultural and forestry possibilities. To accomplish this, Lee’s (2002) GHG version of the Forest and Agricultural Sector Optimization Model (hereafter referred to as FASOMGHG) will be used (FASOM - Adams et al., 1996). This model has forest carbon accounting unified with a detailed representation of the possible mitigation strategies in the agricultural sector adapted from Schneider (2000) and McCarl and Schneider (2001).

FASOMGHG is a 100 year inter-temporal, price-endogenous, mathematical programming model depicting land transfers between the AF sectors in the USA. Model solution portrays a multi-period equilibrium on a decadal basis along with a dynamic simulation of prices, production, management, and consumption within these two sectors under the scenario depicted in the model data. 
Geographic_scope. FASOMGHG divides the USA into 11 regions. Nine of which produce forest products and 10 of which produce agricultural products.

Product_scope. FASOMGHG simulates production of 50 crop and livestock commodities and 56 processed commodities along with 10 forestry commodities.

Land_Transfers. There are period by period land transfer possibilities involving land from: (1) forestry to agriculture in the pasture or cropland categories; (2) agriculture to forestry in either the pasture or cropland categories; (3) cropland to pasture; and (4) pasture to cropland. Many forested tracts are not suitable for agriculture, thus, the model accounts for land that is not mobile between uses. Costs for converting forestland reflect stump removal, land grading, and other factors.

Agricultural Management. The agricultural component depicts activity during each of ten decades. Agricultural output is produced using land, labor, grazing, and irrigation water. Once commodities enter the market, they can go to livestock use, feed mixing, processing, domestic consumption, or export. Imports are also represented. The model structure incorporates the ASM model described by Chang et al. (1992) with Schneider (2000) added GHG features. Demand and supply components are updated between decades. The model uses constant elasticity functions for domestic and export demand as well as factor and import supply. In the first two decades, the solution is required to be within a convex combination of historical crop mixes, following McCarl (1982), but is free to change thereafter. Possibilities for GHGE management are included by incorporating the strategies summarized in Table 1.

Forest_Management. The forest sector model allows multiple harvest age possibilities. Multiple-decade forest production processes are represented by periodic regional timber yields from the Aggregate Timber Land Analysis System (ATLAS - Mills and Kincaid, 1992). Logs are differentiated into sawlogs, pulpwood, and fuelwood for both hardwoods and softwoods, yielding six product classes. Upon harvest, forestlands may be regenerated into forestry or may migrate into agriculture. Forested land is 
differentiated by region, ownership class, age cohort of trees, forest cover type, site productivity class, timber management regime, and suitability of forestland for agriculture use.

Terminal_conditions. Given the model is defined for a finite period; there will be immature trees at the end. Terminal conditions are imposed that value ending immature trees and land remaining in agriculture.

Soil_and_Ecosystem_Saturation. Terrestrial carbon sinks are limited by ecosystem capability in interaction with the management system. In particular, carbon only accumulates until a new equilibrium is reached. FASOMGHG assumes tillage practice change induced carbon gains/losses stop after 30 years; based on West and Post (2002).

Forest carbon accounting is based on the Forest Carbon Budget Model (FORCARB) model as developed by Birdsey (1992) and Birdsey and Heath (1995) and the Harvested Carbon HARVCARB model of Rowe (1992). Forest carbon is accounted in four basic pools, soil, ecosystem, standing trees, and products after harvest.

Biofuel production and use. In FASOMGHG, the potential for biofuel penetration into the energy sector coupled with the cost of production is represented in several ways. Biomass input is modeled to the point in the power plant energy generation process where fuel is fed into the burners. Two biomass production and power plant use scenarios are used: (1) diverting milling residues from traditional pulp and paper or other uses and (2) producing switch grass and short rotation woody crops for biomass. The model also allows the possible use of wood chips from short rotation woody crops for pulp and paper production. Biomass hauling costs are from McCarl et al. (2000). Switch grass and short rotation woody crop production information is from yields and costs of production studies at the Oakridge National Laboratories (Walsh and Graham (1999); Graham et al., 1996). Maximum potential by year for biomass penetration into the electrical energy market data is based on information provided by Haq (Z. Haq, US Department of Energy, Energy Information Administration, Washington, DC, 2003, personal communication). Cellulosic and maize starch-based ethanol were used in the model. 


\section{RESULTS AND IMPLICATIONS}

The fundamental analysis is an examination of AF mitigation strategies that arise under different $\mathrm{CO}_{2}$ equivalent (CO2E) prices. The $\mathrm{CO} 2 \mathrm{E}$ price is applied to $\mathrm{CO}_{2}, \mathrm{CH}_{4}$, and $\mathrm{N}_{2} \mathrm{O}$ emissions/offsets adjusted for their greenhouse gas warming potential. CO2E prices are varied from $\$ 0$ to $\$ 80$ per metric MT. Offset estimates are computed on a total US basis relative to a zero CO2E scenario.

\section{Static Mitigation Quantity}

The strategies employed vary over time. The annuity equivalent offset is used to summarize the strategies with GHG increments discounted at a 4\% rate following Richards (1997). Trends appearing in the results (Table 2 and Figure 1) are:

- At low GHG offset prices the first options chosen are agricultural soil carbon and existing forest stand management largely in the form of longer rotations.

- At higher GHG offset prices biofuel for power plants and afforestation dominate with agricultural soil share reduced from its peak.

- Non- $\mathrm{CO}_{2}$ related strategies largely in the form of livestock and fertilization management are small but rise with the GHG offset price.

- Liquid fuel replacement biofuels do not enter the solution.

Overall, at lower prices, mitigation involves the use of management alternatives complementary to current land uses that continue traditional production. However, at higher prices, biofuels and afforestation appear, displacing the traditional production but generating larger offsets.

Biofuel related results show the dominance of power plant usage as opposed to liquid fuel production. This is largely because the power plant replacement uses little energy 
relative to the offset quantity, but the liquid fuel biofuel replacement uses substantially more energy.

\section{Dynamic GHG Mitigation}

One can look at the results over time. Figures 2 through 4 present the accumulated GHG mitigation credits from forest sequestration, agricultural soil sequestration, power plant feedstock biofuel offsets, and non- $\mathrm{CO}_{2}$ strategies in different GHG offset prices.

At low prices and in the near term, the carbon stock on agricultural soil and in existing forests initially grows rapidly. However, the offset quantity later diminishes and becomes stable with saturation. Carbon stocks in the forest grow for about 40 years at low prices. Non- $\mathrm{CO}_{2}$ strategies continually grow throughout the whole model period. Biofuel is not a factor in the near term as it is too expensive to be part of a low carbon price mitigation plan.

When the prices are higher, the forest carbon stock increases first, and then diminishes. The agricultural soil carbon stock is much less important -- especially in the later decades. Non- $\mathrm{CO}_{2}$ mitigation grows but is not a very large contributor to mitigation. Power plant feedstock biofuel potential grows dramatically (ethanol is not used) over time and becomes the dominant strategy.

Across the results of the various scenarios, several patterns emerge.

- Carbon sequestration, including agricultural soil and forest carbon, and power plant feedstock biofuel offsets are the high quantity mitigation strategies. The importance of these strategies varies by price and time.

- At low prices and in the earlier decades, agricultural soil carbon and existing forest management are dominant. When carbon prices are higher, afforestation and power plant feedstock biofuels are dominant because they have higher per acre carbon offsets. 
- The carbon sequestration activities tend to rise over time then stabilize largely due to saturation phenomena. Soils saturate faster than trees.

- The higher the price, the more carbon stored in the forests in the early decades. However, the intensified forest sequestration comes with a price in that $\mathrm{CO}_{2}$ emissions from forests increase later.

\section{Market Effects and Co-benefits}

The introduction of the GHG offset prices causes changes in land use, tillage, fertilization, crop mix and other management practices, commodity production and consumption, and trade flows. In turn, this causes changes in market conditions and environmental pollutant loadings. Market related results found include: (1) a decline in production of traditional agricultural commodities; (2) a rise in agricultural and short term forest commodity prices; (3) losses in consumer welfare due to higher prices; (4) gains in producer welfare due to higher food prices and GHG related offset payments; and, (5) losses in export earnings.

The environmental impacts include: (1) a drop in the amount of traditionally cropped agricultural land; (2) a drop in irrigated area; (3) an increase in forested land; (4) an increase in biofuel land; and (5) a decline in loadings for nitrogen, phosphorous, and soil erosion into the environment. An interesting result is that pollutant loadings decline substantially at low prices, but, rise at higher prices due to production intensification as land is diverted away from agriculture.

\section{An analysis of biofuel competitiveness}

Key factors in biofuel production involve the subsidy level (carbon price), technical progress, and market penetration. The results show that the carbon price is quite important. At low CO2E prices, biofuels are not important. However, when carbon 
prices exceed \$50 per MT (or about \$15 per MT of $\mathrm{CO}_{2}$ ), biofuels become very important. At even higher prices, biofuels quickly reach their maximum market potential. Removal of market penetration limits shows a great increase in potential biofuel offsets (See Lee (2002) where such caps were not included). Finally, the effect of shifts in the technical progress rate is from the study by McCarl et al. (2000). In that paper it was found that the competitiveness of the biofuel for power plants depends critically on the rate of technical progress continuing without large increases in costs.

\section{FUTURE RESEARCH}

Future biofuel investigation will continue under a US Department of Agriculture (USDA) and US Department of Energy (US DOE) supported project focused on: (1) life cycle analysis of biofuel liquid products and biofuel fired power plant feedstocks in comparison with coal and petroleum in terms of net energy use, greenhouse gas balance, and other environmental emissions; (2) environmental biocomplexity analysis (ElHalwagi, 2003) of socio-economic, technical, and environmental implications of biofuel use; (3) chemical reaction analysis of discharges from coal and biofuel power plants; (4) techno-economic and environmental analysis of co-fed (biomass and fossil fuel) power plants; (5) integrated environmental and economic analysis of biofuel production, including farm level emissions analysis and hydrological pollutant load routing; (6) joint environmental, economic and energy performance modeling of electric turbine and post combustion treatment for different biomass/coal mixes; (7) role of fundamental combustion developments for biofuel usage; and, (8) technological innovations in farm biomass product yields, handling and storage requirements, energy yields from combustion or processing and control of production and processing costs. 


\section{CONCLUSIONS}

This study discussed the reasons why biofuels and other GHG offsets might be adopted by society then conducted a modeling analysis regarding AF sector GHGE mitigation strategies in response to GHG offset prices. Focus was placed on the role of biofuel alternatives in general and over time. The results show that the sectors offer substantial potential to mitigate GHG emissions. Mitigation strategy choices change dynamically depending on price and time. Tillage-based agricultural soil carbon sequestration and forest rotation length induced sequestration are the primary mitigation strategies implemented in early decades and at low prices (below $\$ 10$ per $\mathrm{MT} \mathrm{CO}_{2}$ ). However, both saturate and turn into $\mathrm{CO}_{2}$ sources after 40 to 60 years. On the other hand, power plant feedstock biofuel activities and afforestation become more important in the long run and/or at higher prices. Crop and livestock management are small but steady contributors across the entire spectrum of prices and time periods.

Generally, at high carbon prices, biomass feedstocks can be a way of altering the emission characteristics of US electrical generation but appears to be of limited usefulness in the liquid fuel markets. The competitiveness of biomass depends upon the success of research in developing improved production methods for biofuel crops. The results support the argument that agricultural and forest carbon sequestration provides more time to find long run solutions such as new technologies to halt the increasing ambient GHG concentration as discussed in Marland et al. (2001). It also shows that power plant feedstock biofuels are likely to be an important long-run strategy when GHG offset subsidies are high. 


\section{ACKNOWLEDGEMENTS}

The work underlying this chapter was supported by USDA, the US Environmental

Protection Agency, US DOE, the Sustainable Agriculture and Natural Resource

Management Collaborative Research Support Program and the Texas Agricultural Experiment Station.

\section{REFERENCES}

Mills and Kincaid (1992)

Adams, D., Alig, R. Callaway, J., McCarl, B. and Winnett, S. (1996) The Forest and Agricultural Sector Optimization Model (FASOM): Model Structure and Policy Applications. US Department of Agriculture Forest Service Research Paper PNW-495, Pacific Northwest Research Station, Portland, Oregon.

Birdsey, R. (1992) Prospective Changes in Forest Carbon Storage from Increasing Forest Area and Timber Growth. US Department of Agriculture, US Forest Service, Washington, DC.

Birdsey, R. and Heath, L. (1995) "Carbon Changes in U.S. Forests.” In: Joyce, L (ed.) Climate Change and the Productivity of America's Forests. US Department of Agriculture, US Forest Service, Ft. Collins, Colorado.

Brown, S. (1999) Guidelines for Inventorying and Monitoring Carbon Offsets in Forest Based Projects. Winrock International, Morrilton, Arkansas.

Brown, S., Burnham, M., Delaney, M., Powell, M., Vaca, R. and Moreno, A. (2000) Issues and Challenges for Forest-based Carbon-offset Projects: A Case Study of the Noel Kempff Climate Action Project in Bolivia. Mitigation and Adaptation Strategies for Global Change 5(1):99-121.

Bush, G. (2002) Executive Summary - The Clear Skies Initiative. The White House, Executive Office of the President, Washington, DC. [Accessed 2004.] Available from http://www.whitehouse.gov/news/releases/2002/02/clearskies.html 
Chang, C., McCarl, B, Mjelde, J. and Richardson, J. (1992) Sectoral Implications of Farm Program Modifications. American Journal of Agricultural Economics, 74, 38-49.

El-Halwagi, M. (2003) Industry and Environmental Biocomplexity: Impact, Challenges, and Opportunities for Multidisciplinary Research. Journal of Clean Technologies and Environmental Policy 4(3), 135.

Follett, R., Kimble, J. and Lal, R. (2000) The Potential of U.S. Grazing Land to Sequester Carbon and Mitigate the Greenhouse Effect. CRC Press, Boca Raton, Florida.

Graham, R., Lichtenberg, E., Roningen, V., Shapouri, H. and Walsh, M. (1996) The Economics of Biomass Production in the United States. US Department of Energy, Oak Ridge National Laboratory, BioFuels Feedstock Development Program, Oak Ridge, Tennessee. [Accessed 2004.] Available from http://bioenergy.ornl.gov/papers/bioam95/graham3.html

Intergovernmental Panel on Climate Change. (1996) Climate Change 1995: The IPCC Second Assessment Report, Volume 2: Scientific-Technical Analyses of Impacts, Adaptations, and Mitigation of Climate Change. Watson, R., Zinyowera, M. and Moss, R. (eds.). Cambridge University Press, Cambridge, England.

Intergovernmental Panel on Climate Change. (2001a) Climate Change 2001: Mitigation, IPCC Third Assessment Report: Contributions of IPCC Working Group III. Metz, B., Davidson. O., Swart, R. and Pan, J. (eds.) Cambridge University Press, Cambridge, England.

Intergovernmental Panel on Climate Change (2001b) IPCC Third Assessment Report: Climate Change 2001: The Scientific Basis: A Report of Working Group I of the Intergovernmental Panel on Climate Change. Intergovernmental Panel on Climate Change, Geneva, Switzerland. [Accessed 2004.] Available from http://www.grida.no/climate/ipcc_tar/wg1/index.htm.

Kline D., Hargrove, T. and Vanderlan, C. (1998) The Treatment of Biomass Fuels in Carbon Emissions Trading Systems. Center for Clean Air Policy, Washington, DC. [Accessed 2004.] Available from http://www.ccap.org/pdf/biopub.pdf.

Lal, R., Kimble, J., Follett, R. and Cole, C. (1998) The Potential of U.S. Cropland to Sequester Carbon and Mitigate the Greenhouse Effect. Sleeping Bear Press Inc., Chelsea, Michigan.

Lee, H. (2002) The Dynamic Role for Carbon Sequestration by the U.S. Agricultural and Forest Sectors in Greenhouse Gas Emission Mitigation. PhD dissertation, 
Department of Agricultural Economics, Texas A\&M University, College Station, Texas

Marland, G. and Schlamadinger, B. (1997) Forests for Carbon Sequestration or Fossil Fuel Substitution A Sensitivity Analysis. Biomass and Bioenergy 13:389-397.

Marland, G., McCarl, B. and Schneider, U. (2001) Soil Carbon: Policy and Economics. Climatic Change 51: 101-117.

McCarl, B. (1982) Cropping Activities in Agricultural Sector Models: A Methodological Proposal. American Journal of Agricultural Economics 64(4), 768-772.

McCarl, B. and Schneider, U. (2000) Agriculture's Role in a Greenhouse Gas Emission Mitigation World: An Economic Perspective. Review of Agricultural Economics 22:134-59.

McCarl, B. and Schneider, U. (2001) The Cost of Greenhouse Gas Mitigation in U.S. Agriculture and Forestry. Science 294, 21:2481-2482.

McCarl, B., Adams, D., Alig, R. and Chmelik, J. (2000) Analysis of Biomass Fueled Electrical Powerplants: Implications in the Agricultural and Forestry Sectors. Annals of Operations Research 94, 37-55.

Mills J, Kincaid J (1992) The aggregate timberland assessment system--ATLAS: a comprehensive timber projection model. Portland, OR: U.S. Department of Agriculture, Forest Service, Gen. Tech. Rep. PNW-281. Pacific Northwest Station.

Murray, B.. (2003) Carbon Sequestration: A Jointly Produced Forest Output. In: Sills, E. and Abt, K. (eds). Forests in a Market Economy. Kluwer Academic Publishers, Boston, Massachusetts.

Pew Center (2003) "Analysis of President Bush's Climate Change Plan", http://www.pewclimate.org/policy_center/analyses/response_bushpolicy.cfm.

Reilly, J., R. Prinn, J. Harnisch, J. Fitzmaurice, H. Jacoby, D. Kicklighter, J. Melillo, P. Stone, 1999. “Multi-gas Assessment of the Kyoto Protocol.” Nature 401: 549-55.

Richards, K. R., The time value of carbon in bottom-up studies, Critical Reviews in Science and Technology, 27(special), 279-292, 1997.

Rowe, C. (1992) Carbon Sequestration Impacts of Forestry: Using Experience of Conservation Programs. Presented paper, Symposium on Forest Sector, Trade, and Environmental Impact Models: Theory and Applications. April 30 - May 1, 
1992, Seattle, Washington.

Schneider, U. (2000) Agricultural Sector Analysis on Greenhouse Gas Emission Mitigation in the U.S. PhD dissertation, Department of Agricultural Economics, Texas A\&M University, College Station, Texas.

Schneider, U., and McCarl, B. (2003) Economic Potential of Biomass Based Fuels for Greenhouse Gas Emission Mitigation. Environmental and Resource Economics 24, 291-312.

Skog, K. and Nicholson, G. (2000) Carbon Sequestration in Wood and Paper Products. In: Joyce, L. and Birdsey, R. (eds.) The Impact Of Climate Change On America's Forests: A Technical Document Supporting The 2000 USDA Forest Service RPA Assessment. RMRS-GTR-59. US Department of Agriculture, US Forest Service Rocky Mountain Experiment Station, Fort Collins Colorado.

United Nations Framework Convention on Climate Change (1998) The Convention and Kyoto Protocol. United Nations Framework Convention on Climate Change, Bonn, Germany. [Accessed 2004.] Available from http://www.unfccc.de/resource/convkp.html

US Environmental Protection Agency. (2004) US Emissions Inventory 2004 :Inventory Of U.S. Greenhouse Gas Emissions And Sinks: 1990-2002, EPA 430-R-04-003, April 2004 available at http://yosemite.epa.gov/oar/globalwarming.nsf/content/ResourceCenterPublicatio nsGHGEmissionsUSEmissionsInventory2004.html

Walsh, M. and Graham, R. (1999) Biomass Feedstock Supply Analysis: Production Costs, Land Availability, Yields. US Department of Energy, Oak Ridge National Laboratory, BioFuels Feedstock Development Program, Oak Ridge, Tennessee.

Watson, R. (2000) Report to the Sixth Conference of the Parties of the United Nations Framework Convention on Climate Change. Intergovernmental Panel on Climate Change, Geneva, Switzerland. [Accessed 2004.] Available from http://www.ipcc.ch/press/sp-cop6-2.htm

West, T. and Post, W. (2002) Soil Organic Carbon Sequestration Rates by Tillage and Crop Rotation: A Global Data Analysis. Soil Science Society of America Journal 66:1930-1946. 
Table 1. Mitigation strategies in FASOMGHG

\begin{tabular}{lllll}
\hline & & \multicolumn{2}{c}{ Greenhouse gas affected } \\
\cline { 3 - 5 } Mitigation strategy & Strategy Nature & $\mathrm{CO}_{2}$ & $\mathrm{CH}_{4}$ & $\mathrm{~N}_{2} \mathrm{O}$ \\
\hline Afforestation & Sequestration & $\mathrm{X}$ & & \\
Rotation length & Sequestration & $\mathrm{X}$ & & \\
Timberland management & Sequestration & $\mathrm{X}$ & & \\
Defforestation (avoided) & Sequestration & $\mathrm{X}$ & & \\
Biofuel production & Offset & $\mathrm{X}$ & $\mathrm{X}$ & $\mathrm{X}$ \\
Crop mix alteration & Emission, Sequestration & $\mathrm{X}$ & & $\mathrm{X}$ \\
Rice acreage reduction & Emission & & $\mathrm{X}$ & \\
Crop fertilizer rate reduction & Emission & $\mathrm{X}$ & & $\mathrm{X}$ \\
Other crop input alteration & Emission & $\mathrm{X}$ & & \\
Crop tillage alteration & Sequestration & $\mathrm{X}$ & & \\
Grassland conversion & Sequestration & $\mathrm{X}$ & & \\
Irrigated /dry land conversion & Emission & $\mathrm{X}$ & & $\mathrm{X}$ \\
Livestock management & Emission & & $\mathrm{X}$ & \\
Livestock herd size alteration & Emission & & $\mathrm{X}$ & $\mathrm{X}$ \\
Livestock system change & Emission & $\mathrm{X}$ & $\mathrm{X}$ \\
Liquid manure management & Emission & $\mathrm{X}$ & $\mathrm{X}$ \\
\hline
\end{tabular}


Table 2: Emission Reduction in MMT of $\mathrm{CO}_{2}$ Equivalent

\begin{tabular}{lccccc}
\hline & \multicolumn{5}{c}{ Price in \$ per $\mathrm{MT} \mathrm{CO}_{2}$ Equivalent } \\
\cline { 2 - 6 } & 5 & 15 & 30 & 50 & 80 \\
\hline Afforestation & 2 & 110 & 450 & 845 & 1264 \\
Soil Sequestration & 120 & 153 & 147 & 130 & 105 \\
Biomass Offsets & 17 & 844 & 952 & 957 & 960 \\
CH4\&N2O & 13 & 34 & 65 & 107 & 159 \\
Forest Management 106 & 216 & 313 & 385 & 442 \\
Crop Management & 29 & 56 & 74 & 91 & 106 \\
All Strategies & 288 & 1413 & 2001 & 2514 & 3037 \\
\hline
\end{tabular}

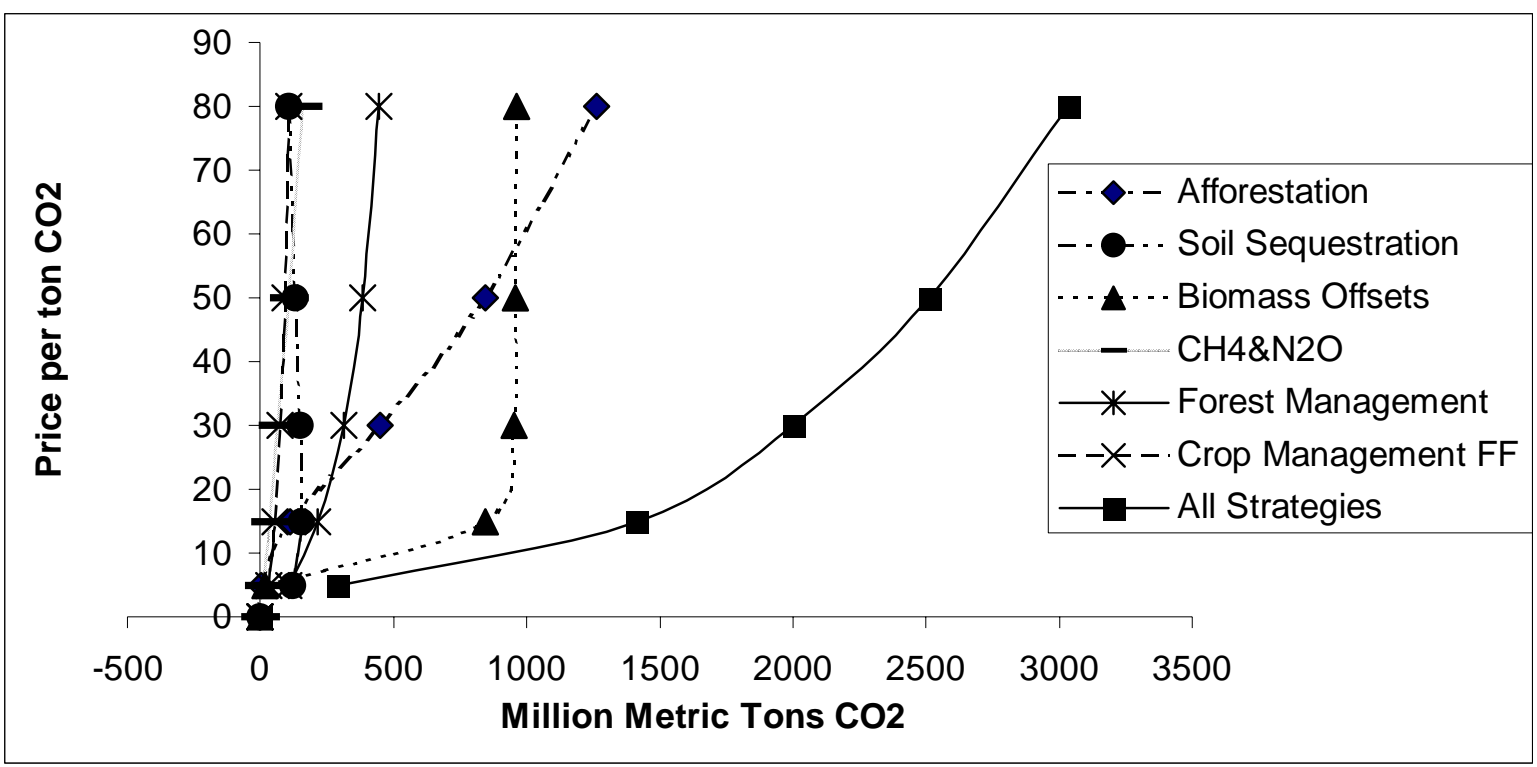


Figure 1. Annualized Mitigation Potential of Chosen Mitigation Tools at Different GHG Offset Prices

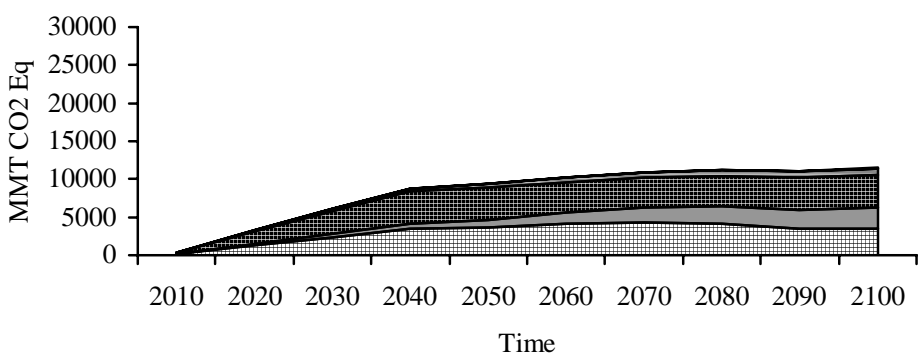

Figure 2. Cumulative Mitigation Contributions from Major Strategies at a $\$ 5 \mathrm{CO}_{2}$ Equivalent Price

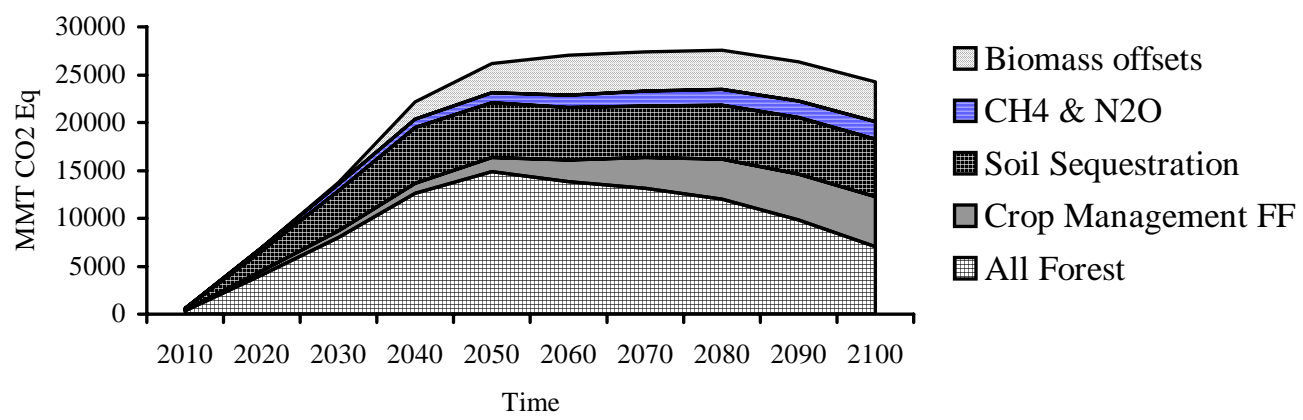

Figure 3. Cumulative mitigation contributions from major strategies at a $\$ 15 \mathrm{CO}_{2}$ Equivalent Price 


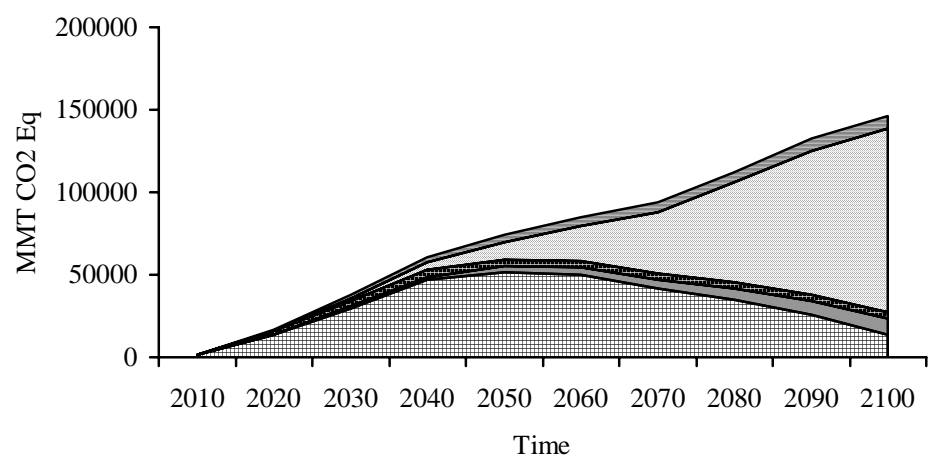

Figure 4. Cumulative Mitigation Contributions from Major Strategies at a $\$ 50 \mathrm{CO}_{2}$ Equivalent Price 